\section{Esophageal Crohn's disease}

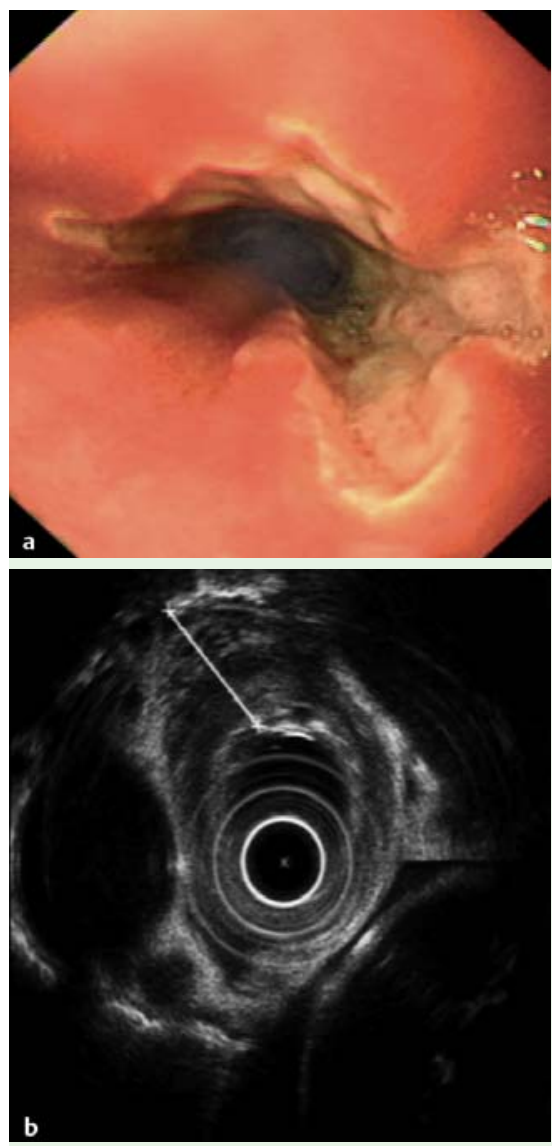

Fig. 1 Endoscopic and endoscopic ultrasonographic appearance of esophageal Crohn's disease. a Before treatment, an esophageal lesion with a central ulcer is seen that took up twothirds of the circumference. The base of the ulcer exhibits a cobblestone-like appearance. $\mathbf{b}$ Endoscopic ultrasonography showed a heterogeneous echo in the esophageal wall with strand-like hyperechoic areas. Two enlarged lymph nodes

Esophageal involvement in Crohn's disease is uncommon event, especially solitary esophageal Crohn's disease, with an incidence ranging from $0.3 \%$ to $2 \%$ [ 1 $3]$. We report a case of solitary esophageal Crohn's disease.

A 46-year-old Chinese woman was admitted to hospital in April 2007, presenting with a history of continuous mouth ulcers, pain on swallowing, and chest pain; she had been unable to take solid food for 5 months. Gastroscopy revealed one huge ulcer in the esophagus, located $28-33 \mathrm{~cm}$ from the upper incisors and around two-thirds of the circumference, with its base of a cobblestone appearance ( $\bullet$ Fig. 1 a). Histological examination of

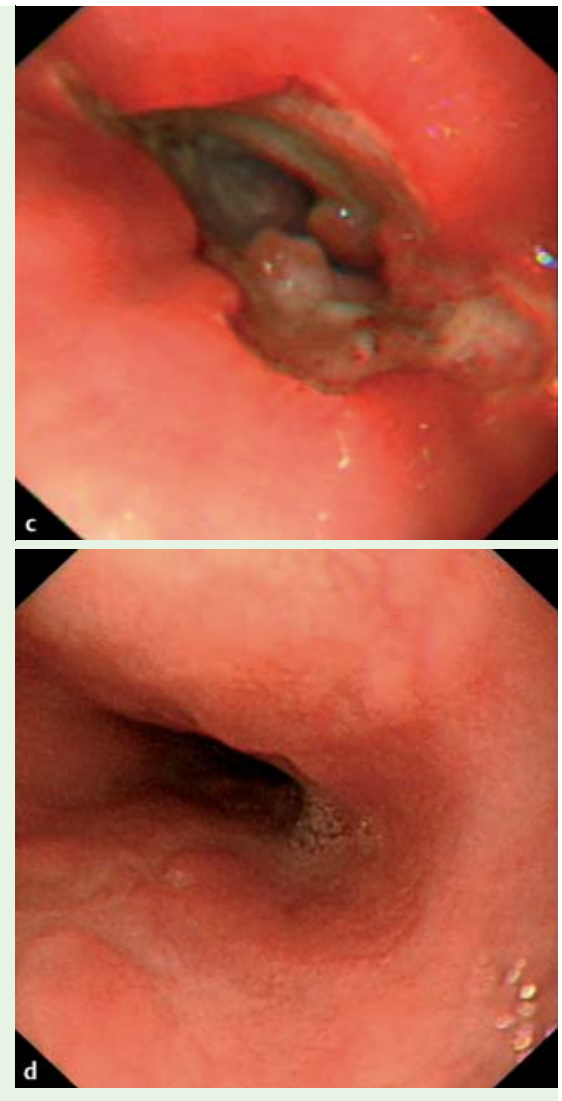

3-4 mm in diameter were observed as a lowecho signal. The thickness of the esophageal wall was $15.4 \mathrm{~mm}$. c After antituberculosis therapy, the lesion spread to the whole circumference with a more obvious cobblestone-like ulcer base. d After appropriate treatment, the ulcer disappeared and the injured mucosa was repaired with only a scar left.

biopsy specimens from the ulcer margin revealed chronic inflammation. Endoscopic ultrasonography showed a heterogeneous hypoechoic lesion with a thickened wall around 9-15 $\mathrm{mm}$ in the esophagus; all five layers of the esophageal wall were disordered, the adventitia was interrupted, and mediastinal lymphadenitis was present ( $\bullet$ Fig. 1 b). Colonoscopy and barium studies of the small intestine as well as capsule endoscopy revealed no abnormality. At first, antituberculosis treatment was applied as a diagnostic therapy, but 1 month later the esophageal ulcer expanded to the full circumference and became deeper ( $\bullet$ Fig. 1 c). Then esophageal Crohn's disease was consid- ered. Treatment started with prednisone (40 mg p.o., q.d.) and olsalazine (1000 mg p.o., t.i.d.). The prednisone was gradually withdrawn over 3 months and the olsalazine (500 mg t.i.d.) was maintained for 1 year. In the follow-up period, gastroscopy showed the ulcer disappearing gradually and the mucosal lesion being completely repaired piece by piece $($ Fig. 1 d).

Endoscopy_UCTN_Code_CCL_1AB_2AC_3AZ

\section{G.-C. Lou' ${ }^{1}$, J.-M. Yang ${ }^{1}$, W. Huang ${ }^{1}$,}

\section{J. Zhang ${ }^{1}$, B. Zhou ${ }^{2}$}

1 Department of Gastroenterology, Zhejiang Provincial People's Hospital, Hangzhou, China

2 Harvard Stem Cell Institute, Children's Hospital Boston and Harvard Medical School, Boston, Massachusetts, USA

\section{References}

1 Naranio-Rodriguez A, Solorzano-Peck G, Lopez-Rubio $F$ et al. Isolated oesophageal involvement of Crohn's disease. Eur J Gastroenterol Hepatol 2003; 15: 1123-1126

2 Heller T, James SP, Drachenberg C et al. Treatment of severe esophageal Crohn's disease with infliximab. Inflamm Bowel Dis 1999; 5: $279-282$

3 Rudolph I, Goldstein F, DiMarino AJ jr. et al. Crohn's disease of the esophagus: three cases and a literature review. Can J Gastroenterol 2001; 15: 117-122

\section{Bibliography}

DOI $10.1055 / \mathrm{s}-0029-1214498$

Endoscopy 2009; 41: E257

(c) Georg Thieme Verlag KG Stuttgart · New York . ISSN 0013-726X

\section{Corresponding author}

\section{J.-M. Yang, MD}

Department of Gastroenterology

Zhejiang Provincial People's Hospital

Hangzhou 310014

China

Fax: +86-571-85131448

jianminyang@hotmail.com 